\title{
Analyzing the Impact of Price Promotion Strategies on Manufacturer Sales Performance
}

\author{
Bingqun Cui', Kejia Yang', Tingjui Chou ${ }^{3}$ \\ ${ }^{1}$ School of Economics and Management, Southwest Jiaotong University, Chengdu, China \\ ${ }^{2}$ School of Business, Renmin University of China, Beijing, China \\ ${ }^{3}$ Cirrus Data Insights Ltd., Taiwan, China \\ Email: bingquncui@163.com
}

Received 8 April 2016; accepted 23 April 2016; published 27 April 2016

Copyright (C) 2016 by authors and Scientific Research Publishing Inc.

This work is licensed under the Creative Commons Attribution International License (CC BY). http://creativecommons.org/licenses/by/4.0/

(c) (i) Open Access

\begin{abstract}
This article studies the influences of three different strategies of distributor price promotion, i.e. award-type price promotion, threat-type price promotion and rebate, on manufacturer's sales performance by empirical research, and analyzes the regulatory effect of promotion strength in the influence of two price promotion strategies on manufacturer's sales performance, thus providing a theoretical foundation and empirical reference for enterprises to reasonably implement distributor price incentive and customer management.
\end{abstract}

\section{Keywords}

Price Promotion Strategies, Sales Performance, Prospect Theory

\section{Introduction}

Nowadays, with the increasingly fierce market competition, more and more manufacturers adopt various price strategies to motivate distributors, so as to increase orders and stimulate sales performance [1]-[3]. The frequent ordering of customers to a company's product is the source of its sales volume and profit. The increase of orders is very crucial for manufacturers. In general, price incentive strategies will stimulate the desire of distributors to place orders, and the accumulated ordering of distributors is the influence of price strategy on manufacturer's sales performance, thus increasing its sales order quantity.

However, some researchers showed that distributors' different responses to different price strategies as well as their different order intentions revealed the influence of price strategy on the ordering of distributors (Cui and $\mathrm{Li}$,

How to cite this paper: Cui, B.Q., Yang, K.J. and Chou, T.J. (2016) Analyzing the Impact of Price Promotion Strategies on Manufacturer Sales Performance. Journal of Service Science and Management, 9, 182-187. 
2015) [4]. Therefore, under the influence of different price incentive strategies, there should be a difference in the quantity manufacturer's orders. Then, which price incentive strategy can bring orders to manufacturers more easily? Which strategy can better increase manufacturer's order quantity? This thesis adopts the Hurdle Regression Model to analyze influences of different price incentive strategies on sales performance.

As a kind of hierarchical regression model, Hurdle Regression Model (Mulahy, 1986) [5] is the extension of traditional count regression model and is mainly used to analyze zero truncated distribution data with a lot of 0 values in the count regression. The occurrence of 0 value in the Hurdle model is the incident with the probability following binomial distribution, thus determining whether 0 value occurs through discrete choice model. For values larger than 0 , the traditional count model is used for solution. The expected value of incident frequency is the overlapped result of two models [6].

\section{Research Design}

\subsection{Data Introduction}

In recent years, with the rapid rise of China's economy, the rapid development of real estate and related industries has driven the rapid expansion of domestic new building material industry, and the competition in building material industry has been fiercer, and China's new building material enterprises have closely reached the level of developed countries in scale, technology, management and marketing. Typically, most of them have adopted the sales model of depending on distributors.

Therefore, this study determines the data source in a large new building material group company in China. This group company has over 40 manufacturing plants reasonably distributed in China, its sales network is throughout the country, and it is a strong representative in the industry. Taking into account the influence of factors such as regional economic difference and cultural habit, we focus on data selection in a total of 348 distributors in Beijing, Tianjin, Hebei and Inner Mongolia in north China, Sichuan and Chongqing in the southwest region. This study obtains the complete records and all sales data on incentive policies implemented for these 348 distributors from January 1, 2011 to June 30, 2013 from the company’s internal sales database.

\subsection{Research Design}

1) Price is an important factor affecting customer's purchase decision, and it has the important decisive effect on whether, when and which product the customers want to buy, as well as their purchase quantity and other purchase decisions [7] [8]. Price promotion is increasingly applied in the marketing practice as an integral part of marketing mix and an important marketing tool of promoting sales growth. In general, the manufacturers implement the incentive strategy for distributors in a form of price promotion.

According to corporate marketing practice, we separately study three most-commonly-used incentive strategies, namely two price promotion types and one rebate type: the first type is the award-type price promotion strategy (referred to as the reward-type promotion), which is the reduced price of a specific percentage or amount given by manufacturers to distributors on specific products in a specified period; the second type is the threat-type price promotion strategy (referred to as the threat type promotion), which is the increased price of a specific percentage or amount notified by manufacturers to distributors in advance on specific products after a specified period, and which is also the original price that will be adopted when an order is placed before a specified period; the third type is the "rebate strategy", which means the order rebate of a certain percentage is given by the manufacturers to specified distributors on the specified products ordered by the distributors in a specified period after the manufacturers set a task quota for specified distributors and the distributors finish this task. In general, manufacturers will carry out the strategy of rebate percentage linked to task, namely, set up different task levels responding to different rebate percentages or amounts. The rebate percentage will be higher if more tasks are finished. Meanwhile, this rebate strategy will generally cover most of distributors.

This study focuses on the influence of above-mentioned three typical distributor incentive strategies on manufacturer's sales performance. This study uses the price change percentage (promotion intensity) as the proxy variable to incentive strategy, namely using the preferential price percentage that distributors can enjoy in the specified period to measure the influence of award-type promotion; using the increased price percentage that will be notified to distributors in advance on the specific products after a specified period to measure the threat-type promotion; using the percentage of distributors enjoying rebate in distributors benefiting from pro- 
motion strategies, also the percentage of distributors simultaneously enjoying rebate in each promotion strategy to measure the influence of threat-type promotion.

2) The distributor's order is affected by many factors such as regional economic and consumption level, distributor's business strategy and scale as well as season and product variety. Meanwhile, due to limitations on inventory and costs, in case the order frequency of distributor in the unit time is pre-determined, the order quantity will be larger in case of longer duration of promotion strategy, and the total order quantity will be larger in case of more distributors benefiting from promotion strategy. To control these impacts, this thesis includes the duration of promotion strategy, number of beneficial distributors, scale of distributor, year, region, product variety and other control variables in the model.

3) Based on the selected data, this study needs to select the count regression model to analyze the influence of price incentive strategy on manufacturer's order performance. The count regression model is based on Poisson Regression Model, which is a probability distribution used to describe the frequency of random incidents occurring in the unit time or space. The Poisson Regression Model has an important assumption, namely the expected value of dependent variable should be equal to variance. In this study, the mean of order quantity during promotion is far less than variance. This phenomenon is called as over-discrete phenomenon, which is generally analyzed through negative binomial regression (Cameron and Trivedi, 1998) [9]. The reason for over-discrete order quantity is that distributors do not order any specified goods during promotion, so there is no order placed in $65 \%$ promotion activities. Therefore, it is necessary to separately analyze whether there is any order during incentive strategy as well as the order quantity. Thus, this thesis adopts the Hurdle Regression Model. This thesis will select logistic regression as the discrete selection part in the Hurdle Model to analyze whether different price incentive strategies affect order; under the promotion strategy that produces order, this thesis uses the count regression model and the binomial regression to correct the underestimation of actual data variation level by Poisson Regression Model, thus analyzing the influence of price promotion strategy on manufacturer's order quantity.

\section{Empirical Analysis}

\subsection{Data Descriptive}

Descriptive statistics show that the regional distribution of sample distributors selected is relatively even. 59\% of distributors are selected from Southwest China, and $41 \%$ of distributors are selected from North China. The average annual sale of sample distributors is 17.7 million yuan, indicating that these distributors have a strong marketing capacity.

In terms of price promotion strategy, from 2011 to the first half of 2013, this group company had a total of 1803 distributor promotion strategies on different regions and different product lines. The average duration of these promotion strategies was two weeks, the longest duration was nearly one year, most of them were award-type promotion, accounting for $92 \%$ of first two promotion means, and the average discount was $20 \%$. The average price rise percentage of the threat-type promotion was $8 \%$. Though the threat-type promotion only accounted for $8 \%$ of two promotion means, it was adopted by this group company in different years and regions. The third type of incentive measure is rebate strategy, covering most of distributors. Among distributors benefiting from single promotion, the average benefit rate of rebate strategy is $44 \%$.

\subsection{Analysis of Influence of Two Promotion Strategies on Manufacturer's Sales Order Performance}

Based on the selected data, this study selects the Hurdle Regression Model to analyze the influence of price incentive strategy on manufacturer's sales order performance. The summary of the research model is shown in Table 1.

Model (1) measures the overall impact of the price incentive strategy on manufacturer's sales order performance, and it measures the total order quantity of main distributors benefiting from promotion strategy implemented in North China and Southwest China from January 1, 2011 to June 30, 2013. From the perspective of control variable, firstly, the order quantity will be larger in case of longer duration of promotion, which meets our assumption on promotion duration and order quantity. Secondly, there is a negative correlation between sales volume of distributor and order quantity, indicating that the quantity of order obtained by manufacturers 
Table 1. The summary of the research model.

\begin{tabular}{|c|c|c|}
\hline Variable (order quantity) & Model(1) & Mode (2) \\
\hline \multicolumn{3}{|l|}{ Logit regression coefficient } \\
\hline Intercept & $3.286^{* *}(1.006)$ & $2.498^{*}(1.266)$ \\
\hline Duration & $0.013^{* * *}(0.004)$ & $0.013^{* * *}(0.004)$ \\
\hline Promotion strategies (reward-type promotion) & $-0.219(0.225)$ & $0.609(0.813)$ \\
\hline Promotion intensity & - & $8.680(8.489)$ \\
\hline Promotion intensity $\times$ Reward-type promotion & - & $-9.075(8.583)$ \\
\hline Distributor’s scale (natural logarithm) & $-0.149^{*}(0.059)$ & $-0.149^{*}(0.059)$ \\
\hline Time & control & control \\
\hline Region & control & control \\
\hline \multicolumn{3}{|l|}{ Negative binomial regression coefficient } \\
\hline Intercept & $5.822^{* * *}(1.000)$ & $3.607^{* *}(1.273)$ \\
\hline Duration & $0.021^{* * *}(0.002)$ & $0.020^{* * *}(0.002)$ \\
\hline Promotion strategies (reward-type promotion) & $-0.513^{* *}(0.170)$ & $1.849^{*}(0.874)$ \\
\hline Promotion intensity & - & $20.347^{*}(8.856)$ \\
\hline Promotion intensity $\times$ Reward-type promotion & - & $-22.764^{*}(8.961)$ \\
\hline Distributor's scale (natural logarithm) & $-0.116^{*}(0.055)$ & $-0.103^{\dagger}(0.055)$ \\
\hline Time & control & control \\
\hline Region & control & control \\
\hline Log (Measures of Dispersion) & $-0.434^{* * * *}(0.076)$ & $-0.409^{* * *}(0.075)$ \\
\hline Log-likelihood & -3962 & -3956 \\
\hline Sample size & 1803 & 1803 \\
\hline
\end{tabular}

during promotion is smaller in case of larger average sales volume of beneficial distributors. Similarly, there is a negative correlation between the number of distributors benefiting from promotion strategy and the order quantity.

In terms of distributor price incentive strategy, Model (1) shows that two types of price promotion strategies have no significant difference in the presence of orders $(\beta=-0.219, p>0.1)$. However, in the price promotion strategy with order existing, relative to threat-type promotion, for the total order quantity in a single promotion, the award-type promotion has the negative effect $(\beta=-0.513, p<0.01)$, which indicates that the threat-type promotion can bring more orders than award-type promotion. In this regard, through the pure descriptive statistics, it can be significantly found that the average order quantity in all threat-type promotions is 89 , while it is 24 in the award-type promotion. Of course, the average duration of threat-type promotion is 30 days, while the average duration of award-type promotion is 13 days, so the former is greatly longer than the latter. Model (1) shows that the longer duration can cause larger probability and quantity of order obtained in this promotion. Therefore, the influence of time factor on the order quantity in these two promotion strategies needs to be excluded. The measurement results based on average daily order quantity show that the threat-type promotion is superior to the award-type promotion in the quantity of order obtained in unit time. The average daily order quantity in the threat-type promotion is 2.94, higher than that in the award-type promotion, which is 2.37 . It indicates that, in case the information on price rise is obtained, more distributors place an order, thus bringing more orders to manufacturers.

Prospect Theory suggests that, if the risk is uncertain, the subject of decision-making shows the features of "risk aversion" and "diminishing marginal utility". The conclusion in this study verifies the different responses 
of decision-making subject to "benefit" and "loss" [10]. Facing the threat-type promotion strategy, the decision-making subject usually gives stronger response to price rise than price fall, thus bringing more orders to manufacturers.

\subsection{Analysis of Regulatory Effect of Promotion Intensity in Influence of Promotion Strategy on Manufacturer's Sales Order Performance}

Model (1) measures the influence of award-type promotion and threat-type promotion on manufacturer's sales order performance from an overall perspective. However, the intensity of price promotion strategy (promotion intensity) similarly affects customer's order tendency. Therefore, the author uses Model (2) to analyze the regulatory effect of promotion intensity in influence of promotion strategy on manufacturer's sales order performance.

The regulatory effect analysis shows that in the promotion strategy with order placed, the quantity of order obtained by manufacturers will be larger in case of stronger intensity of threat-type promotion; while the quantity of order obtained by manufacturers will be smaller in case of stronger intensity of award-type promotion (Figure 1).

\subsection{Analysis of Influence of Rebate Strategy on Manufacturer's Sales Order Performance}

For another type of price incentive strategy, the statistic results show that the influence of rebate strategy on order quantity is also significant. Model (1) also examines the influence of rebate strategy on single promotion. Results show that the order quantity in single promotion is negatively correlated to the proportion of distributors enjoying rebate strategy among distributors benefiting from promotion $(\beta=-0.902, p<0.01)$. Namely, if more distributors among those benefiting from single promotion enjoy rebate strategy, it will be easier for the promotion to bring orders.

Results also show that the order quantity is positively correlated to proportion of distributors enjoying rebate strategy $(\beta=1.732, p<0.001)$. Namely, if more distributors enjoy rebate strategy and benefit single promotion at the same time, the order quantity will be larger. It fully indicates the regulatory effect of rebate strategy in promotion strategy and order performance. Manufacturers adopt rebate strategy for more distributors, which can help bring more orders in the single promotion, and increase the order quantity.

In his study, Turner (1998) [11] pointed out when customers were engaged an activity, their determination would be stronger when they wanted to gain more rewards. According to the Prospect Theory, relative to uncertain "profit", the decision-making subject will be more inclined to consider it as certain "profit". For the rebate strategy given by manufacturers, after finishing rebate tasks, distributors will certainly obtain proportionate refund of purchase price, namely, the rebate strategy of manufacturers will certainly make distributors obtain ex-

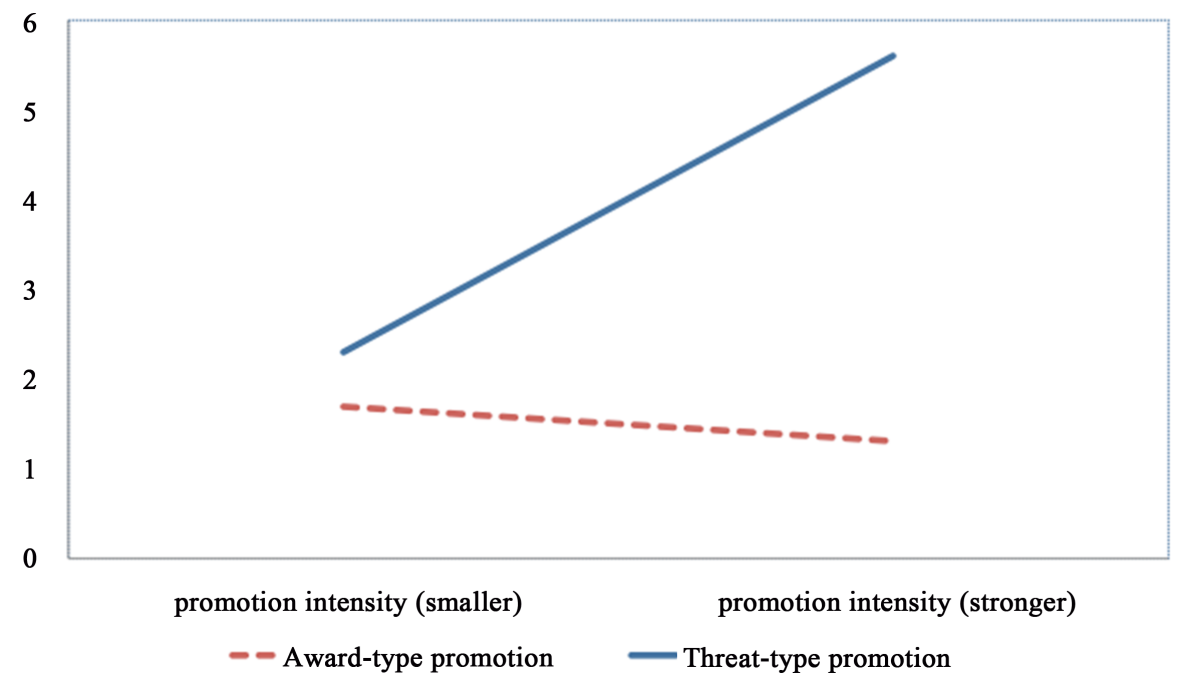

Figure 1. Regulatory effect of promotion intensity. 
pected "profit". Under the promotion of such expected "profit", it would be naturally easier for each promotion of manufacturers to produce orders and bring more orders to manufacturers.

\section{Conclusions and Suggestions}

\subsection{Conclusions}

Based on the Hurdle Regression Model, this thesis empirically studies the impacts of three distributor incentive strategies, namely award-type price promotion, threat-type price promotion and rebate, on manufacturer's sales performance, then empirically examines the difference in the quantity of orders caused by the incentive strategies of manufacturers, and provides new perspective and direction for the further study of relationship between manufacturer and distributor.

According to relevant researches in this thesis, there is no significant difference in terms of the existence of orders for manufacturers under the award-type promotion and threat-type promotion. However, if orders exist, the threat-type promotion can bring more orders than award-type promotion. Meanwhile, it is found that the threat-type promotion is superior to the award-type promotion in the quantity of orders obtained in unit time. The regulatory effect analysis shows that the promotion intensity plays a significant regulatory role in the relationship between promotion strategy and manufacturer's sales performance. Moreover, it is also discovered that the rebate strategy adopted by manufacturers for more distributors can help bring more orders in the single promotion and increase order quantity.

\subsection{Suggestions}

The conclusions in this study provide certain empirical reference for manufacturers to implement distributor price incentive strategy. It is suggested that manufacturers need to consider the actual situations of different manufacturers when implementing distributor price incentive strategy, and determine the purpose of each promotion or incentive according to company's actual situation. This study selects a new building material enterprise as the data source. There may be some differences in the market features, customer features and customer behaviors among different industries, so the applicability to other industries needs further verification by sampling data from different industries.

\section{References}

[1] Ramaswami, S.N. and Srinivasan, S.S. (1998) Analyzing the Impact of Promotions on Manufacturer and Retailer Performance, Journal of Marketing Channels, 6, 131-145 http://dx.doi.org/10.1300/J049v06n03_07

[2] Hastie, R. (2001) Problems for Judgement and Decision Making. Annual Review of Psychology, 52, 653-684.

[3] White, R. (2002) Best Practice: Sales Promotions and the Brand. Admap, 436.

[4] Cui, B.Q. and Li, Y.P. (2015) Research on Mechanism of Distributors' Frequent Ordering Intention: A Prospect Theory Perspective. Modern Economy, 6, 1167-1172. http://dx.doi.org/10.4236/me.2015.611110

[5] Mullahy, J. (1986) Specification and Testing of Some Modified Count Data Models. Journal of Econometrics, 33, 341-365. http://dx.doi.org/10.1016/0304-4076(86)90002-3

[6] King, G. (1989) Event Count Models for International Relations: Generalizations and Applications. International Studies Quarterly, 123-147. http://dx.doi.org/10.2307/2600534

[7] Gupta, S. (1988) Impact of Sales Promotions on When, What, and How Much to Buy. Journal of Marketing, 25, 342-355. http://dx.doi.org/10.2307/3172945

[8] Gupta, S. and Cooper, L.G. (1992) The Discounting of Discounts and Promotion Thresholds. Journal of Consumer Research, 19, 401-411. http://dx.doi.org/10.1086/209310

[9] Cameron, A.C. and Trivedi, P.K. (1998) Regression Analysis of Count Data. Cambridge University Press, Cambridge. http://dx.doi.org/10.1017/CBO9780511814365

[10] Kahneman, D. and Tverskey, A. (1979) Prospect Theory: An Analysis of Decision under Risk. Econometrica, 47, 263-291. http://dx.doi.org/10.2307/1914185

[11] Turner, J.H. (1998) The Structure of Sociological Theory. Thomson Learning, California. 